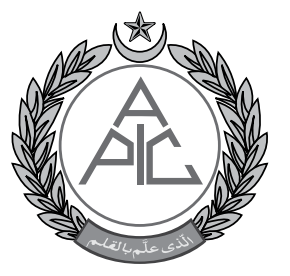

\title{
Accepting a chronic kidney disease patient for perioperative management: a narrative review of key aspects
}

\author{
Habib Mohammad Reazaul Karim¹, MD, DNB (Anaesth), IDCCM \\ (Crit Care Med), Chinmaya Kumar Panda ${ }^{1}$, MD, PDF (Crit Care Med), \\ Subrata Kumar Singha ${ }^{1}$, MD, PDCC (Cardiac Anaesth)
}

\begin{abstract}
Chronic kidney disease is one of the leading co-morbidity at present. With the increasing prevalence of diabetes mellitus and hypertension, more and more peoples are developing diabetic and hypertensive nephropathy. As chronic kidney disease patient can present as an asymptomatic stable patient in one end and a multi-organ involved complicated end-stage disease in other ends, their management plan also varies. The serum creatinine levels of as low as $1.5 \mathrm{mg} \%$ have been linked to perioperative major cardiac events like myocardial infarction and arrest; these patients poses a challenge to the perioperative team. Moreover, a chance of developing acute kidney injury on the chronic kidney disease is also higher. These patients are also often elderly, with diabetes mellitus and/or hypertension. Therefore, accepting such patient for perioperative care needs systematic and meticulous approach. Preoperative assessment, risk stratification, and optimization play a great role. Both intraoperative and postoperative management needs a tailored approach. The present narrative review is prepared to give the current insight on these aspects.
\end{abstract}

Department of Anesthesiology \& Intensive Care, All India Institute of Medical Sciences, Raipur. India

Correspondence:

Dr Habib Mohammad Reazaul Karim, Department of Anesthesiology \& Intensive Care, All India Institute of Medical Sciences (AllMS), Great Eastern Rd, AlIMS Campus, Tatibandh, Chhattisgarh 492099, (India)

Received: 28 Oct 2018

Reviewed: 30 Oct 2018

Corrected: 7 Nov 2018

Accepted: 7 Nov 2018

Key words: Chronic Kidney Disease; Preoperative Assessment; Risk Stratification; Hemodialysis; Anesthesia; Intensive Care Unit

\begin{abstract}
Abbreviations used: AKI - Acute kidney injury; CKD - Chronic kidney disease; ESRD End stage renal disease; eGFR: estimated Glomerular Filtration Rate; HD - Hemodilaysis; GFR - Glomerular filtration rate; KDIGO - The Kidney Disease: Improving Global Outcomes, RCRI - Revised Cardiac Risk Index; RRT- Renal Replacement Therapy
\end{abstract}

Citation: Karim HMR, Panda CK, Singha SK. Accepting a chronic kidney disease patient for perioperative management: a narrative review of key aspects. Anaesth Pain \& Intensive Care 2018;22 Suppl 1:S29-S38

\section{INTRODUCTION}

Chronic kidney disease (CKD) has a high prevalence worldwide. ${ }^{1}$ These patients will undergo surgical procedures many a time related to dialysis or surgeries related to their co-morbidities. Major surgeries like joint replacements, renal transplants are also increasingly done now a day. A patient with CKD may present to a hospital as an asymptomatic, stable patient; symptomatic, stable on medical management; symptomatic, stable on renal replacement therapy or even directly in the advanced / end-stage renal disease with acute life-threatening complications. ${ }^{2,3}$ As the patient may present in any stage of disease and with varied clinical manifestations; their management plan also varies. The approach of such patient often needs to be multidisciplinary, yet, for better planning and management, the anesthesiologist needs to be versed with the pathophysiology and implications of these changes during perioperative care, especially for anesthesia. A proper preoperative evaluation of the CKD patient is required for formulating perioperative care. Although guidelines and literature on the diagnosis and management of CKD patients 
are there, ${ }^{4}$ specific guidelines for perioperative management and approach is limited. The present review is prepared to give the current insight on these aspects.

\section{PATHOPHYSIOLOGY AND STAGES OF CKD}

Chronic kidney disease is a multitude of systemic disorders primarily arising with the involvement of the kidney. The mechanism of development of this disorder basically depends on two phenomena; a) loss of a significant number of functional nephrons, and b) compensatory reversible / irreversible pathological changes in the remaining nephrons. It is the end result of various kidney diseases. Reduction in the number of nephrons lead to hyperfiltration by the rest of the nephrons; Estimates of single nephron glomerular filtration rate (GFR) in humans support hyperfiltration as a relevant pathophysiologic mechanism; $;^{5}$ on a long run, distortion of glomerular architecture, abnormal podocyte function, and disruption of the filtration barrier lead to sclerosis. Renin-angiotensin system has a major role in the adaptive hyperfiltration as well as subsequent sclerosis (flow diagram 1). Reduction in GFR is the first reliable parameter and is used to stage the CKD. Staging of CKD was done based on GFR (G-stages) by the National Kidney Foundation, ${ }^{6}$ and also adopted by the Kidney Disease: Improving Global Outcomes (KDIGO) as below (Table 1); ${ }^{4}$

The KDIGO guidelines also recommend using albuminuria levels along with GFR to improve prognostic accuracy in the assessment of $\mathrm{CKD} .{ }^{4}$ Patients with stage G4 and G5 disease, involve multiple organ systems, showing a state of dyssynchronous cross talk among them. Uremia in an advanced stage gives

Table 1: Staging of CKD based on GFR (G-stages) by the National Kidney Foundation

\begin{tabular}{l|c|l}
\multicolumn{1}{c|}{ ategory } & $\begin{array}{c}\text { eGFR (ml/ } \\
\left.\mathbf{m i n} / \mathbf{1 . 7 3} \mathbf{~ m}^{\mathbf{2}}\right)\end{array}$ & \multicolumn{1}{c}{ Terms used to describe } \\
\hline G1 & $\geq 90$ & Normal or high \\
\hline G2 & $60-89$ & Mildly decreased* \\
\hline G3a & $45-59$ & Mildly to moderately decreased \\
\hline G3b & $30-44$ & Moderately to severely decreased \\
\hline G4 & $15-29$ & $\begin{array}{l}\text { Severely decreased (advanced renal } \\
\text { disease) }\end{array}$ \\
\hline G5 & $<15$ & End stage renal disease (ESRD) \\
\hline
\end{tabular}

*Relative to young adult level. (eGFR- estimated glomerular filtration rate, ESRD- End-stage renal disease). In the absence of evidence of kidney damage, neither GFR category G1 nor G2 fulfils the criteria for chronic kidney disease. rise to many metabolic and endocrine abnormalities leading to the deranged metabolism of carbohydrates, protein and fat, decreased erythropoietin production, malnutrition. Metabolisms of parathyroid hormone (PTH), fibroblastic growth factor-23, insulin, glucagon, sex hormones are getting disturbed as CKD progresses to stage G4. The disharmony of the internal milieu produces systemic inflammatory changes, atherosclerotic and calcific changes in vessels, dysplastic bones, especially in children. Knowledge of the above malfunctions holds the key for delivering a safe anesthesia to a patient of CKD posted for various surgeries.

\section{ORGAN-SPECIFIC CHANGES WITH POTENTIAL PERIOPERATIVE IMPLICATIONS}

Cardiovascular System: Cardiovascular diseases in CKD are the major cause of mortality with higher relative risk in young patients. Calcific changes and sodium and water imbalance contribute significantly towards congestive heart failure, left ventricular hypertrophy (LVH), ischemic heart disease, sudden death, cerebrovascular accidents, and peripheral artery diseases. ${ }^{7,8} \mathrm{LVH}$ is an independent risk factor for producing arrhythmia, myocardial infarction, and heart failure. Diuretics can be used to reduce fluid overload. Patient with the diuretic resistant disease may need dialysis before a scheduled surgery. Permanent arterio-venous fistula also produces fluid overload and status has to be confirmed before surgery. Furthermore, raised renin-angiotensin levels cause endothelial hypertrophy and sclerosis. ${ }^{8}$ Administered erythropoietin can also cause hypertension. The Angiotensin-converting enzyme (ACE) inhibitor or an Angiotensin II receptor blocker (ARB), may slow the disease process and even preserve renal function, and is recommended for controlling the blood pressure (BP). ${ }^{9}$ The intraoperative increased incidence of hypotension in such patients who are receiving ACE/ARB drugs needs to be considered. ${ }^{10}$

Respiratory System: CKD can complicate respiratory system in multiple ways, including pulmonary edema, fibrinous pleuritis, pulmonary calcification, etc. ${ }^{11}$ Sleep disturbances and sleep apnea are extremely common in patients with ESRD. ${ }^{11}$ Patients may present with hypoxemia, hypercapnia and ventilation-perfusion mismatch due to fluid overload. Fluid overload is closely associated with restrictive and obstructive respiratory abnormalities in patients receiving renal replacement therapy (RRT) ${ }^{12}$ Measures to restrict salt and fluid, diuretics are the mainstay for symptom alleviation. 
If symptoms persist despite conservative measures, RRT like hemodilaysis (HD) can be used as required and it has been shown to improve pulmonary function test results. ${ }^{12}$

Central Nervous System: Generalized fatigue, malaise, lack of concentration, impaired cognition gradually leading to mental obtundation, seizure, coma, and death. ${ }^{13}$ Patients on HD may present with dehydration, vomiting, and hypotension and rarely dialysis disequilibrium syndrome due to changes in extracellular fluid volume and subsequent cerebral edema. ${ }^{14}$ These facts need to be remembered while obtaining the consent of evaluating postoperative recovery and progression of such patients.

Hematological and Coagulation System: In CKD, erythropoietin-producing cells in the kidney i.e. peritubular and endothelial cells of the cortex and outer medulla are damaged resulting in reduced erythrocyte production and differentiation. Decreased red cell lifespan, increased hemolysis and bleeding, repeated loss during HD, uremia induced bone marrow suppression and iron, folate, and vitamin $\mathrm{B}_{6}$ and $\mathrm{B}_{12}$ deficiencies altogether produces anemia. Increased cardiac output compensates the tissue oxygenation but gradually land up in high output failure. Erythropoiesis-stimulating agents are preferred over blood transfusion for the treatment of severe anemia in these patients. ${ }^{15} \mathrm{KDIGO}$ and the Renal Association guideline recommend not using blood transfusion if a patient is waiting for renal transplant unless and until it becomes essential. ${ }^{15,16}$ The CKD patients are having a bleeding tendency because of dysfunctional platelets attributing to uremic thrombocytopathy. Defective interaction of von-Willebrand factor with platelet glycoprotein IIb-IIIa receptors, reduced platelet adenosine diphosphate content, and reduced thromboxane A2 cause an abnormal platelet function. ${ }^{17}$ These aspects need to be considered while evaluating such patients and planning management, especially regional anesthesia.

Bone mineral disease: Hyperphosphatemia is a common complication of $\mathrm{CKD}$ but a relatively late event. Initially, the hypersecretion of PTH maintains calcium and phosphate balance. But gradually secondary hyperparathyroidism lead to the development of renal osteodystrophy and multiple major bone disorders. ${ }^{18}$ Calcitriol is secreted from the kidney to directly suppress the secretion of PTH. However, as the disease progresses to stage G4, circulating calcitriol levels begin to fall resulting in a decompensated bone disease. Clinically patient presents with bone pain deformed long bones in weight-bearing age and subsequent fracture. Care should be taken during positioning before surgery. Intubation process should be gentle, keeping in mind of minimal movement at the atlantoaxial junction.

Fluid, Electrolyte and Acid-Base Balance: When the GFR falls below $10-15 \mathrm{ml} / \mathrm{min} / 1.73 \mathrm{~m}^{2}$, the homeostasis of sodium and water and free acids get compromised severely leading to volume overload. This results in relative hyponatremia, hyperchloremia, hyperkalemia, and metabolic acidosis. Some authors claimed that a reduction in sodium intake halts the disease progression by increasing intra-glomerular pressure over a period of time. ${ }^{19}$ Water restriction is indicated only when hyponatremia is clinically relevant. Retention of potassium is not directly proportional to reduced GFR. Rather it is affected by impaired aldosterone secretion in distal nephron and impaired gestorintestinal tract function. Failure of both the defences produces hyperkalemia and in the late course led to cardiac abnormalities. Increased dietary potassium intake, protein catabolism, hemolysis, hemorrhage, transfusion of stored red blood cells, and metabolic acidosis etc. make the situation even worse. In addition, some medications (e.g. Renin-AngiotensinAldosterone system inhibitors and spironolactone and other potassium-sparing diuretics) also produce hyperkalemia. Optimum potassium level usually can be obtained by dietary restriction, avoidance of certain medications and medical management.

Metabolic acidosis is frequently seen early in the course of the disease. Although kidney is able to acidify the urine, the ability to produce ammonia decreases which are further aggravated by hyperkalemia. Hyperkalemia and hyperchloremic acidosis together produce a state of non-anion gap metabolic acidosis. As the kidney function deteriorates, daily excretion of acids falls down to $30-40 \mathrm{mmol}$. The $\mathrm{pH}<7.35$ is rare and treatment with sodium bicarbonate generally maintains the homeostasis when the serum bicarbonate concentration falls below 20-23 $\mathrm{mmol} / \mathrm{L} .^{20}$

Gastrointestinal System: The gastric and small intestinal epithelial tight junctions get disrupted in CKD. ${ }^{21}$ Erosive gastritis and duodenitis are common, ${ }^{22}$ leading to anorexia, nausea, vomiting, gastrointestinal bleeding, diarrhea, delayed gastric emptying time, increased acidity and gastric volume necessitate the use of $\mathrm{H}_{2}$ blockers and proton pump inhibitors. Rapid sequence intubation has to be considered for these patients if general anesthesia is planned. 


\section{PREOPERATIVE EVALUATION}

The pre-anesthesia evaluation is done for comprehensive assessment of the patient's health; including the functional reserves in context to a surgery/intervention planned and risk stratify for any potential complications during the perioperative period. This also includes optimization of the patient if indicated and planning for anesthesia and postoperative care.

Pre anesthesia Assessment: It should include, at a minimum, patient interview, a focused examination of the airway, lungs, and heart, review of pertinent medical records, indicated preoperative tests and consultations with specialists if necessary. ${ }^{23,2} 4$ Patients' interview for the evaluation of patients with chronic renal disease planned for a surgery should be focusing on knowing the etiology and the severity (level of renal function) of renal failure; to find the clue on complications due to chronic renal disease, etc. The interview should also include a history of comorbidities and functional status of the patient. The severity of the disease will be indicated from the history of urine output, need of dialysis and frequency of dialysis, history of admission to hospital with fluid and electrolyte imbalance etc. GFR can be estimated from serum creatinine level by using the CockroftGault equation and can aid us in classifying the stage of renal failure. ${ }^{25} \mathrm{~A}$ focused yet detailed clinical examination of the cardiovascular and respiratory system is necessary which may give clue to fluid overload, heart failure, uncontrolled hypertension, etc.

Laboratory investigations aids in both preoperative evaluation and risk stratification. It can also guide the team towards optimization needed. However, routine laboratory testing is not recommended. ${ }^{24,26}$ The routine practice has been shown to be subjecting the patient to both unnecessary testing and delay. ${ }^{27}$ It has been also noted that routine testing may not be adequate for severely ill (i.e. ASA- IV) patients. ${ }^{28}$ The impact of routine testing in changing perioperative anesthetic management is also shown to be unfavorable for the patients. ${ }^{29}$ Rather, laboratory testing should be patients' disease and surgery-specific. ${ }^{30}$ Comorbidity based preoperative laboratory testing is likely to be more impactful in changing perioperative anesthetic management. ${ }^{31}$

CKD patients often have comorbidities and fluid and electrolyte imbalance. Therefore, preoperative testing should target towards knowing/establishing the severity, presence of electrolyte imbalance and establishing comorbid condition if suspected from history and clinical examinations. As such patients can have anemia and platelet abnormality, complete blood count in such patient is advisable. The National Institute of Healthcare and Clinical Excellence (NICE) and the Association of Anaesthetists of Great Britain and Ireland recommend that the patients with the severe renal disease should undergo full blood count and electrocardiography. ${ }^{26,32}$ Patients with any kind of renal disease should also undergo serum electrolytes, blood urea and creatinine estimation. ${ }^{26,27,32} \mathrm{~A}$ preoperative chest $\mathrm{x}$-ray may be done if clinical and history suggests any abnormality or the patient is planned to undergo critical care management in the postoperative period. ${ }^{26,27,32}$ Often, CKD is due to diabetes mellitus and if so, blood glucose level estimation is recommended. ESRD patients are likely to have hyperkaliemia, hyponatremia, hypertension, ischemic heart disease, congestive heart failure, metabolic acidosis, and even circulatory collapse. Although, routine echocardiography is not indicated for non-cardiac surgeries, ${ }^{24,26}$ in ESRD patients with cardiorespiratory symptoms planned for NICE major plus grade surgery, it may be necessary or justifiable. Routine urine examination is likely to find albuminuria and sediments which may be helpful for confirming the diagnosis. In this context, it is to be remembered that the patient usually attends pre-anesthesia clinics with known of diagnosed condition; therefore, asking again a routine urine examination is usually not required. Moreover, urinary sediments or albuminuria findings in known chronic renal disease patient is unlikely to change or modify anesthetic management. However, quantitative estimation of urinary albumin and creatinine in spot urine may help us in establishing the severity of CKD by using urinary albumin to creatinine ratio (ACR). ACR >300) refers to severe disease. This is again cannot be regarded as a preoperative test for undergoing surgery, rather, it is a diagnostic and stratification test. As these patients are having albuminuria and serum albumin can affect anesthetic drug pharmacokinetic; serum albumin level determination becomes necessary. However, a complete panel of liver function test can be only justified if congestive heart failure is suspected from history and clinical examination.

Risk Stratification: It is required for informed and shared decision making and planning alternative / additional management if required. Risk stratification of CKD patient undergoing a surgery also depends on the surgery planned. Both renal and cardiovascular risk during the perioperative period should be assessed and noted. Serum creatinine level of $>$ 
$2 \mathrm{mg} \%$ is regarded as one of the risk factors to predict perioperative cardiac morbidity and mortality as described in the revised cardiac risk index (RCRI). ${ }^{33}$ Although RCRI is regarded as gold standard, other risk predictors like reconstructed cardiac risk index (R-RCRI), ${ }^{34}$ myocardial infarction or cardiac arrest (MICA) calculator, ${ }^{35}$ or the American College of Surgeons surgical risk calculator (ACS-SRC), ${ }^{36}$ can also be used. Comparison of these risk calculators has shown that all these calculators are equally effective in defining low-risk patients. ${ }^{37}$ However, the MICA was found to be better in defining high-risk patients. ${ }^{37}$ The guidelines for preoperative cardiovascular evaluation of non-cardiac surgical patients by American College of Cardiology/American Heart Association and European Society of Cardiology and the European Society of Anaesthesiology also recommend the use of any clinical risk indices including RCRI to risk stratify the patient and decision making for the need of the further cardiac evaluation. ${ }^{38,39}$ It is to be noted that the MICA includes serum creatinine of $>1.5 \mathrm{mg} /$ $\mathrm{dl}$ as one of the risk factors. ${ }^{35}$ However, mere presence of a serum creatinine level of $>1.5$ or $2 \mathrm{mg} / \mathrm{dl}$ does not indicate that the patient may be at high risk if the patient is relatively young and not having other comorbidity or complications, and these patients can safely proceed for non-cardiac surgeries without further cardiac evaluation. ${ }^{38,40}$ However, the scenario is not so rosy, especially in the low socioeconomic and developing countries where a good number of CKD patients present for the first time to the hospital with advanced grade/end stage renal disease. If the cause of the CKD is diabetes and the patient is either elderly or presenting with heart failure features, they will need further cardiac evaluation and optimization. ${ }^{38}$ The decision to further evaluate also depends on the invasiveness of the surgery planned. ${ }^{26,38}$

The American Society of Anesthesiologists - physical status, ${ }^{41}$ also risk stratifies and predicts the medical morbidity and mortality reliably and independently following surgery. ${ }^{42}$ The MICA risk calculator also includes it as one of the risk factors to predict 30-day morbidity and mortality from myocardial infarction and cardiac arrest in patients undergoing noncardiac surgeries. ${ }^{35}$ Evidence suggests that the risk of early mortality after surgery begins to rise more steeply once eGFR falls below $60 \mathrm{~mL} / \mathrm{min} / 1.73 \mathrm{~m}^{2}{ }^{23}$ Severe stage stratified by preoperative eGFR levels was found to be effectively predicting postoperative renal replacement therapy in type-A aortic dissection patients. ${ }^{44}$ On admission eGFR provides prognostic information in acute surgical settings too; eGFR < $60 \mathrm{~mL} / \mathrm{min} / 1.73 \mathrm{~m}^{2}$ was associated with increased 30 and 90-day mortality ${ }^{45} \mathrm{~A}$ preoperative poor renal function has been shown to be associated with increased postoperative length of stay in the hospital after coronary artery bypass graft. ${ }^{46}$ Preoperative renal impairment and hypoalbuminemia were associated with a requirement for postoperative HD in cardiac surgical patients. ${ }^{47}$

\section{PREOPERATIVE OPTIMIZATION}

If the surgery planned is not an urgent or emergency and patients renal and comorbid status is likely to improve with preoperative medical management, the patient should be optimized before taking up for elective surgery. This is, however, dependant of the invasiveness and nature of the surgery planned too. A CKD patient posted for vascular access surgery for starting HD is unlikely to require optimization unless the patient is very much unstable from a hemodynamic point of view. On the other hand, if the patient is posted for major surgeries, cardiovascular surgeries, renal transplant, etc., patients with ESRD or advanced renal failure will require preoperative optimization. ${ }^{48}$ As ESRD involves multi-organ systems; preoperative optimization may even need a cardiologist and nephrologists' consultation and inter-disciplinary management. However, a stable CKD patient on RRT or not yet started on RRT, posted for minor or intermediate class surgery without any clue of cardiac abnormality from history, physical examination, and electrocardiogram, do not require a cardiologist consultation or intervention. ${ }^{48}$ The cardiologist referral should be based on the patient and disease-specific. ${ }^{49}$ These patients often have an electrolyte imbalance, especially hyperkalemia, and hypocalcemia; which needs to be optimized to an acceptable level before proceeding for elective surgeries. Although hyperkalemia in CKD patients is well tolerated and poses less threat to the patient as compared to the patient with normal renal function, ${ }^{50}$ it is advisable to keep $\mathrm{K}^{+}$level < $5.5 \mathrm{meq} / \mathrm{L}$ before taking up for elective surgeries. ${ }^{51} \mathrm{In}$ intractable metabolic and electrolyte disturbances, fluid overload; consultation from a nephrologist and intervention like HD may be needed for optimization. Preoperative HD may be needed in ESRD patients if there is a problem with fluid or $\mathrm{K}^{+}$control, planned for major surgery and on maintenance $\mathrm{HD}$. It is usually done the day before the scheduled surgery. ${ }^{48}$ These patients are often having hypertension and diabetes, which may also need optimization before surgery. They are also often on antiplatelet and deep vein thrombosis prophylaxis, which also needs to be managed and optimized as per guidelines. ${ }^{52} \mathrm{~A}$ patient with multiple abnormalities often needs to be shifted 
to intensive care one to two days prior for optimization and closed monitoring and management.

\section{MANAGEMENT OVERVIEW}

In a very large observational study, including more than 75,000 patients undergoing general surgery, preoperative kidney malfunction was strongly associated with the development of postoperative acute kidney injury (AKI) (i.e. 27\% AKI). ${ }^{53}$ On the similar plight, The CKD guidelines recommend that all patients with CKD are considered to be at risk for AKI. ${ }^{4}$ Therefore, the importance of meticulously preserving kidney functions throughout the perioperative period is very important and this should be done both during the intraoperative and postoperative period.

Vascular access: These patients may have difficult venous access due to edema. Current or potential future fistula sites should be avoided for cannulation. The forearm and antecubital veins if possible should also be avoided. Central venous access may also be difficult because of previous dialysis sheath, ultrasound assistance is necessary for placement of catheter. ${ }^{54} \mathrm{HD}$ catheter should not be used to deliver fluid/drugs as far as possible.

Interventions to prevent the decline of pre-existing renal dysfunction: Over the past decades, several interventions have been studied that provide some help to alleviate the pre-existing kidney dysfunction. The kidney protective measures like avoiding hydroxyethyl starch (HES), nephrotoxic medications, and contrast, targeted hemodynamics management, maintenance of global and microperfusion, etc., ${ }^{55}$ should be considered throughout. Evidence-Based Guideline for the management of high BP in adults, suggests a BP goal of $<140 / 90 \mathrm{mmHg}$ in patients with CKD. ${ }^{56}$ However, this recommendation and goal are for long-term management. Although, a specific guideline for an upper acceptable limit of preoperative $\mathrm{BP}$ in CKD patient is not available, yet, a patient can be accepted for elective surgery if the preoperative BP is $<180 / 105 \mathrm{mmHg} .{ }^{57}$ Moreover, these patients often have higher BP and their auto regulations are also set at higher levels. Still, it will be prudent to reduce the blood pressure (if presented with high BP, e.g. 180/100) by $20 \%$ during the intraoperative period,$^{58}$ and then slowly targeting towards the goal in the postoperative period over the next few days. If the patient has an acute cardiovascular emergency, neurologic signs or symptoms, acute renal failure, or a postoperative complication that is exacerbated by the elevated $\mathrm{BP}$, immediate treatment of severe perioperative hypertension is warranted using intravenous antihypertensive. ${ }^{58} \mathrm{~A}$ mean arterial pressure of $65 \mathrm{mmHg}$ may be suboptimal and predispose the patient to AKI in chronic hypertensive patients. ${ }^{59}$ As intraoperative hypotension adversely affects the renal microvasculature and has been shown to be associated with increased 30-day operative mortality in noncardiac surgery, ${ }^{60}$ maintenance of BP within $20 \%$ of baseline can be regarded as paramount especially for those who are at risk of developing AKI.

Although it is established that deranged glycemic control is an independent risk factor for the development of CKD, it yet unknown whether acute hyperglycemia predisposes a patient to AKI. A study enrolling 474 diabetic patients with acute myocardial infarction, evaluated the role of acute and chronic hyperglycemia on AKI and found that on admission hyperglycemia alone cannot predict AKI.$^{61}$ Chronic hyperglycemia is an important determinant. There is still a lack of clarity over the blood glucose level that has to be maintained and until further concrete clarifications glycemic control with blood glucose levels of $110-150 \mathrm{mg} / \mathrm{dl}$ seems to be reasonable and is recommended by the KDIGO for AKI. ${ }^{4}$ However, elective non-cardiac surgery is usually not postponed if blood sugar (BS) is $<400 \mathrm{mg} \% .^{62,63}$ Insulin therapy can be adjusted/started if required for preoperative optimization if blood sugar is not within the goal, and a BS of $180-220 \mathrm{mg} \%$ is well accepted during the perioperative period. It has been noted that preoperative BP between 160/100 - 179/109 $\mathrm{mmHg}$ and $\mathrm{BS}>250-399 \mathrm{mg} \%$ frequently needs medication change with consultations, but the changes in the anesthetic management were not much. ${ }^{64}$ Invasive hemodynamic monitoring may be required during both intraoperative and postoperative ICU care depending on the patients' condition.

The use of intravenous fluids in the perioperative period is a routine practice which compensated for blood, fluid and third space losses. The CKD patients too have an impaired ability to concentrate or dilute urine. Studies on critically ill patients have shown that any weight gain together with the formation of organ edema leads to AKI. ${ }^{65}$ However, the intraoperative use of diuretics is not recommended except for the management of severe fluid overload. ${ }^{4}$ Moreover, not only the amount of fluid but also the kind of fluid to be used are also controversial and have to be considered carefully. Crystalloids, in particular, $0.9 \%$ saline solution is known to cause hyperchloremic acidosis and renal vasoconstriction when infused in large quantities. This contributes to the sharp rise in the risk of developing AKI.$^{66} \mathrm{HES}$ is known for its harmful effect on renal function and coagulation. ${ }^{67,68}$ 
In the $6 \mathrm{~S}$ trial ${ }^{68}$ the need for renal replacement therapy was significantly higher in the HES group compared to the Ringer acetate group, particularly in patient pre-existing renal dysfunction. But, there exists some uncertainty and clarity regarding the use of HES in CKD patients routinely. All the information is taken together, an adequate perioperative control to ensure hemodynamic stability is crucial. Guidelines recommend using isotonic crystalloids rather than colloids in the absence of hemorrhagic shock and avoiding the use of diuretics and other nephrotoxic agents in such subset of patients. ${ }^{4}$ Analgesia should be taken care well and multimodal analgesia with regional anesthesia as one modality will be better, NSAIDs should be avoided.

Most of the patient who are having advanced or ESRD, have to undergo major or major plus grade of surgeries will require postoperative management in intensive care. The management principle is similar to the intraoperative period. Close monitoring and management of fluid, hemodynamics, metabolic derangement, anemia, nutrition, etc is important. ${ }^{69}$ Drugs selection to prevent nephrotoxic drugs; monitoring of kidney function by estimating serial serum creatinine and creatinine clearance is required and drug dose should be adjusted accordingly. ${ }^{69}$ If the patient develops AKI on stable CKD, or if the patient was on maintenance $\mathrm{HD}$, the patient will require postoperative $\mathrm{HD}$. At present there is no clear consensus on when to start HD in AKI, but the accepted urgent indications for HD in such patients generally include; refractory fluid overload, severe hyperkalemia $(>6.5 \mathrm{mEq} / \mathrm{L})$ or rapidly rising potassium levels refractory to medical management, signs of uremia, (i.e. pericarditis, encephalopathy, or an otherwise unexplained decline in mental status), severe metabolic acidosis ( $\mathrm{pH}<7.1)$ etc. ${ }^{70}$ If a patient undergoes $\mathrm{HD}$, drug dose should be adjusted accordingly.

\section{CONCLUSION}

An increasing number of patients with CKD are requiring surgery. The presentation of CKD patient is very much variable including asymptomatic existence. These patients require proper risk stratification before undergoing surgery. Nonemergent cases may be postponed till such patients are optimized. Nephrotoxic drugs or the drugs taking the renal route for elimination need to be avoided or discontinued or adjusted. Optimal hemodynamic to ensure adequate renal perfusion appears to be preventive for precipitation of AKI. Fluid and electrolyte imbalance needs special attention. The level of care and monitoring required vary with the severity of the CKD and invasiveness of surgery planned. Stage G4 and G5 should be managed in a setup with HD and intensive care facility in a multidisciplinary approach.

Acknowledgment: None

Conflicts of interests: None

Funding and financial support: None

Competing interest: None

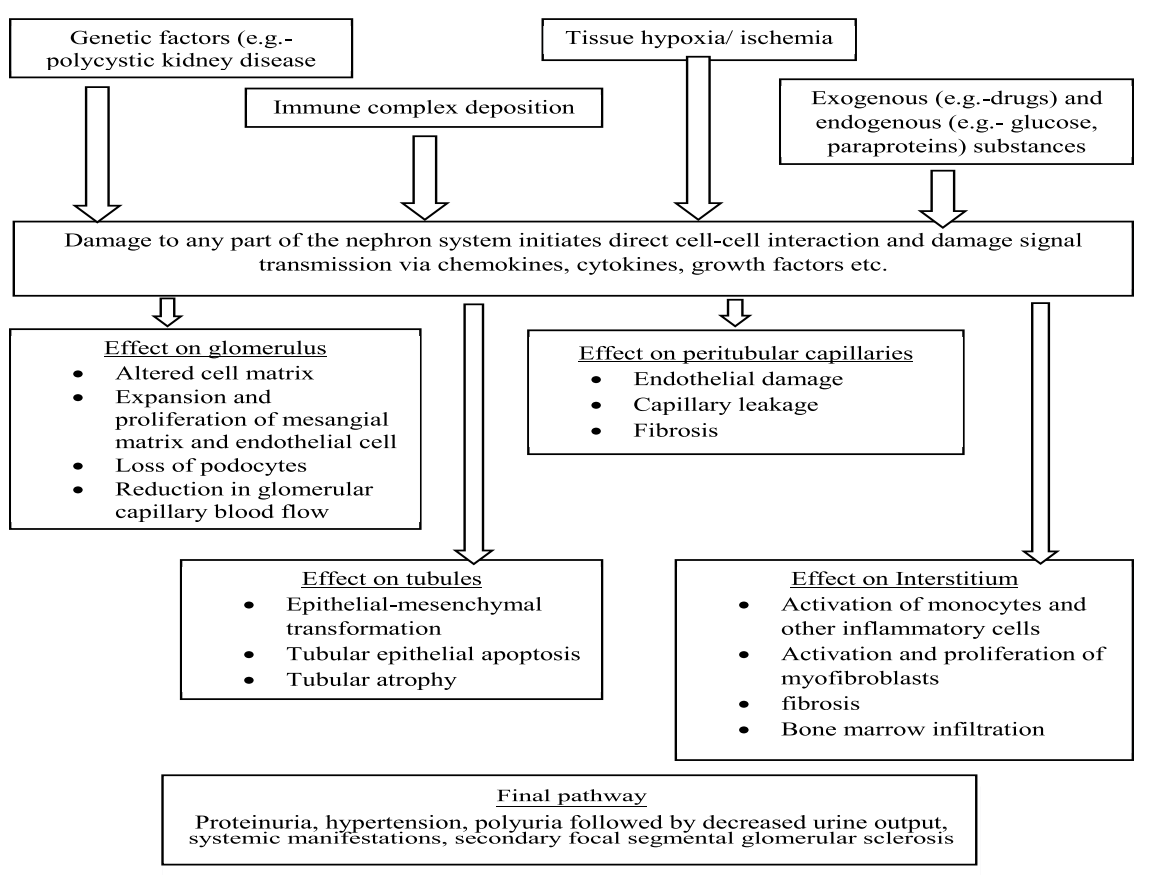

Flow diagram 1: Pathophysiology of chronic kidney 


\section{REFERENCES}

1. Hill NR, Fatoba ST, Oke JL, Hirst JA, O'Callaghan CA, Lasserson DS, Richard Hobbs FD. Global Prevalence of Chronic Kidney Disease - A Systematic Review and Meta-Analysis. PLoS One 2016;11(7):e0158765. [PubMed] [Full text] [Crossref]

2. Amoako YA, Laryea D0, Bedu-Addo $\mathrm{G}$, Andoh H, Awuku YA. Clinical and demographic characteristics of chronic kidney disease patients in a tertiary facility in Ghana. Pan Afr Med J 2014;18:274. [PubMed] [Full text] [Crossref]

3. Chen N, Wang W, Huang Y, Shen P, Pei $\mathrm{D}, \mathrm{Yu} \mathrm{H}$, et al. Community-based study on CKD subjects and the associated risk factors. Nephrol Dial Transplant 2009;24:2117-23. [PubMed] [Full text] [Crossref]

4. Kidney Disease: Improving Global Outcomes (KDIGO) CKD Work Group. KDIG0 2012 Clinical Practice Guideline for the Evaluation and Management of Chronic Kidney Disease. Kidney Int Suppl 2013;3:1-150. [Full text pdf] [Crossref]

5. Denic A, Mathew J, Lerman LO, Lieske JC, Larson JJ, Alexander MP, et al. Single-Nephron Glomerular Filtration Rate in Healthy Adults. N Engl J Med 2017;376:2349 - 57. [PubMed] [Full text] [Crossref]

6. Levey AS, Coresh J, Balk E, Kausz AT, Levin A, Steffes MW, et al; National Kidney Foundation. National Kidney Foundation practice guidelines for chronic kidney disease: evaluation, classification, and stratification. Ann Intern Med 2003;139:137-47. [PubMed] [Full text] [Crossref]

7. Amann K, Tyralla K. Cardiovascular changes in chronic renal failure-pathogenesis and therapy. Clin Nephrol 2002;58 Suppl 1:S62-72. [PubMed]

8. London GM. The Clinical Epidemiology of Cardiovascular Diseases in Chronic Kidney Disease: Cardiovascular Disease In Chronic Renal Failure: Pathophysiologic Aspects. Semin Dial 2003;16:85-94. [PubMed] [Full text] [Crossref]

9. Burden R, Tomson C; Guideline Development Committee, Joint Specialty Committee on Renal Disease of the Royal College of Physicians of
London and the Renal Association. Identification, management and referral of adults with chronic kidney disease: concise guidelines. Clin Med (Lond) 2005;5:635-42. [PubMed] [Full text] [Crossref]

10. Hollmann C, Fernandes NL, Biccard BM. A Systematic Review of Outcomes Associated With Withholding or Continuing Angiotensin-Converting Enzyme Inhibitors and Angiotensin Receptor Blockers Before Noncardiac Surgery. Anesth Analg 2018;127:67887. [PubMed] [Full text] [Crossref]

11. PiersonDJ. Respiratory considerations in the patient with renal failure. Respir Care 2006;51:413-22. [PubMed] [Full text pdf]

12. Yılmaz S, Yildirim Y, Yilmaz Z, Kara AV, Taylan M, Demir M, et al. Pulmonary Function in Patients with End-Stage Renal Disease: Effects of Hemodialysis and Fluid Overload. Med Sci Monit 2016;22:2779-84. [PubMed] [Full text] [Crossref]

13. Renjen PN, Chaudhari D, Sagar G, Jasuja S. Neurology of renal disorders. Neurol India 2018;66:1637. [PubMed] [Full text] [Crossref]

14. Arieff Al, Massry SG, Barrientos A, Kleeman CR. Brain water and electrolyte metabolism in uremia: effects of slow and rapid hemodialysis. Kidney Int 1973;4:177-87. [PubMed] [Full text pdf]

15. Mikhail A, Brown C, Williams JA, Mathrani V, Shrivastava R, Evans $J$, et al. Renal Association clinical practice guideline on Anaemia of Chronic Kidney Disease. BMC Nephrol 2017;18(1):345. [PubMed] [Full text] [Crossref]

16. Kidney Disease: Improving Global Outcomes (KDIGO) Anemia Work Group. KDIGO clinical practice guideline for anemia in chronic kidney disease. Kidney Int Suppl 2012;2:279335. [Full text pdf]

17. Rabelink TJ, Zwaginga JJ, Koomans HA, Sixma JJ. Thrombosis and hemostasis in renal disease. Kidney Int 1994;46:287-96. [PubMed] [Full text] [Crossref]

18. Hruska KA, Teitelbaum SL. Renal osteodystrophy. N Engl J Med 1995;333:166-74. [PubMed] [Full text] [Crossref]
19. Weir MR, Fink JC. Salt intake and progression of chronic kidney disease: an overlooked modifiable exposure? A commentary. Am J Kidney Dis 2005;45:176 -88. [PubMed] [Full text] [Crossref]

20. Adamczak M, Masajtis-Zagajewska A, Mazanowska 0, Madziarska K, Stompór T, Wi $\square$ cek A. Diagnosis and Treatment of Metabolic Acidosis in Patients with Chronic Kidney Disease - Position Statement of the Working Group of the Polish Society of Nephrology. Kidney Blood Press Res 2018;43:959-69. [PubMed] [Full text] [Crossref]

21. Vaziri ND, Yuan J, Nazertehrani S, Ni Z, Liu S. Chronic kidney disease causes disruption of gastric and small intestinal epithelial tight junction. Am J Nephrol 2013;38:99-103. [PubMed] [Full text] [Crossref]

22. Thomas R, Panackal C, John M, Joshi $H$, Mathai S, Kattickaran J, et al. Gastrointestinal complications in patients with chronic kidney disease--a 5-year retrospective study from a tertiary referral center. Ren Fail 2013;35:49-55. [PubMed] [Full text] [Crossref]

23. BJ Sweitzer. Preanesthesia evaluation for noncardiac surgery. In Crowley $M$ (editor) UpToDate. Waltham, MA: UpToDate Inc. 2018 Mar 29 [cited 2018 Oct 23]. Available from: https://www.uptodate.com/contents/ preanesthesia-evaluation-fornoncardiac-surgery

24. Committee on Standards and Practice Parameters, Apfelbaum JL, Connis RT, Nickinovich DG; American Society of Anesthesiologists Task Force on Preanesthesia Evaluation, Pasternak LR, Arens JF, Caplan RA, Connis RT, Fleisher LA, FlowerdewR, etal. Practice advisory for preanesthesia evaluation: an updated report by the American Society of Anesthesiologists Task Force on Preanesthesia Evaluation. Anesthesiology 2012;116:522-38. [PubMed] [Full text] [Crossref]

25. Cockroft DW, Gault MN. Prediction of creatinine clearance from serum creatinine. Nephron 1976;16:31-41. [PubMed] [Full text] [Crossref]

26. National Guideline Centre (UK). Preoperative Tests (Update): Routine 
Preoperative Tests for Elective Surgery. London: National Institute for Health and Care Excellence (UK); 2016. [Last accessed on 2018 0ct 23]. Available from: https://www. nice.org.uk/guidance/ng45/chapter/ recommendations [PubMed] [Full text]

27. Karim HM, Yunus M, Bhattacharyya P. An observational cohort study on pre-operative investigations and referrals: How far are we following recommendations? Indian J Anaesth 2016;60:552-9. [PubMed] [Full text] [Crossref]

28. Garcia AP, Pastorio $K A$, Nunes $R L$, Locks GF, Almeida MC. Indication of preoperative tests according to clinical criteria: Need for supervision. Rev Bras Anestesiol 2014;64:54-61. [PubMed] [Full text] [Crossref]

29. Reazaul Karim HM, Prakash A, Sahoo SK, Narayan A, Vijayan V. Abnormal routine pre-operative test results and their impact on anaesthetic management: An observational study. Indian J Anaesth 2018;62:23-8. [PubMed] [Full text] [Crossref]

30. Böhmer AB, Wappler F, Zwissler B. Preoperative Risk AssessmentFrom Routine Tests to Individualized Investigation. Dtsch Ärztebl Int 2014;111:437-46. [PubMed] [Full text] [Crossref]

31. Rajaram N, Karim HM, Prakash A, Sahoo SK, Dhar M, Narayan A. Prevalence and impact of abnormal routine pre-operative test results among elective surgical patients with or without co-morbidity: An observational comparative study. Niger Postgrad Med J 2018;25:121-5. [PubMed] [Full text] [Crossref]

32. Association of Anaesthetists of Great Britain \& Ireland. AAGBI safety guideline. Pre-operative Assessment and Patient Preparation: The Role of the Anaesthetist-2. London: AAGBI; 2010 Jan. [cited 2018 0ct 25]. Available from: https:// www.aagbi.org/sites/default/files/ preop2010.pdf

33. Lee TH, Marcantonio ER, Mangione CM, Thomas EJ, Polanczyk CA, Cook $\mathrm{EF}$, et al. Derivation and prospective validation of a simple index for prediction of cardiac risk of major noncardiac surgery. Circulation 1999; 100:1043-9. [PubMed] [Full text]

34. Davis C, Tait G, Carroll J, Wijeysundera
DN, Beattie WS. The Revised Cardiac Risk Index in the new millennium: a single-centre prospective cohort re-evaluation of the original variables in 9,519 consecutive elective surgical patients. Can J Anaesth. 2013;60:855-63. [PubMed] [Full text] [Crossref]

35. Gupta PK, Gupta H, Sundaram A, Kaushik M, Fang X, et al. Development and validation of a risk calculator for prediction of cardiac risk after surgery. Circulation. 2011;124:3817. [PubMed] [Full text] [Crossref]

36. Bilimoria KY, Liu Y, Paruch JL, Zhou L, Kmiecik TE, Ko CY, et al. Development and evaluation of the universal ACS NSQIP surgical risk calculator: a decision aid and informed consent tool for patients and surgeons. J Am Coll Surg 2013;217:833842 (e831-e833). [PubMed] [Full text] [Crossref]

37. Cohn SL, Fernandez Ros N. Comparison of 4 Cardiac Risk Calculators in Predicting Postoperative Cardiac Complications After Noncardiac Operations. Am J Cardiol 2018;121:125-30. [PubMed] [Full text] [Crossref]

38. Fleisher LA, Fleischmann $\mathrm{KE}$, Auerbach $A D$, Barnason $S A$, Beckman JA, Bozkurt B. 2014 ACC/ AHA guideline on perioperative cardiovascular evaluation and management of patients undergoing noncardiac surgery: a report of the American College of Cardiology/ American Heart Association Task Force on Practice Guidelines. Circulation 2014;130:e278-333. [PubMed] [Full text] [Crossref]

39. Kristensen SD, Knuuti J, Saraste A, Anker S, Bøtker HE, Hert SD, et al.; Authors/Task Force Members. 2014 ESC/ESA Guidelines on noncardiac surgery: cardiovascular assessment and management: The Joint Task Force on non-cardiac surgery: cardiovascular assessment and management of the European Society of Cardiology (ESC) and the European Society of Anaesthesiology (ESA). Eur Heart J 2014;35:2383431. [PubMed] [Full text] [Crossref]

40. Rafiq A, Sklyar E, Bella JN. Cardiac Evaluation and Monitoring of Patients Undergoing Noncardiac Surgery. Health Serv Insights 2017;9:1178632916686074.
[PubMed] [Full text] [Crossref]

41. ASA House of Delegates. ASA Physical Status Classification System. 2014 Oct 15 [cited 2018 Oct 24]. Available from: http:// www.asahq.org/resources/clinicalinformation/asa-physical-statusclassification-system

42. Hackett NJ, De Oliveira GS, Jain UK, Kim JY. ASA class is a reliable independent predictor of medical complications and mortality following surgery. Int J Surg 2015;18:184-90. [PubMed] [Full text] [Crossref]

43. Mooney JF, Ranasinghe I, Chow CK, Perkovic V, Barzi F, Zoungas S, et al. Preoperative estimates of glomerular filtration rate as predictors of outcome after surgery: a systematic review and meta-analysis. Anesthesiology 2013;118:809-14.[PubMed] [Full text] [Crossref]

44. Imasaka K, Tayama E, Tomita Y. Preoperative renal function and surgical outcomes in patients with acute type A aortic dissection. Interact Cardiovasc Thorac Surg 2015;20:470-6. [PubMed] [Full text] [Crossref]

45. Evans LA, Goeteyn J, Carter B, Greig M, Tay HS, McCormack C, et al. Preoperative kidney function linked to mortality and readmission outcomes at day 90 and 30 in older emergency surgical patients. Eur Geriatr Med 2017;8:216-20. [Full text] [Crossref]

46. LaPar DJ, Rich JB, Isbell JM, Brooks $\mathrm{CH}$, Crosby IK, Yarboro LT, et al. Preoperative Renal Function Predicts Hospital Costs and Length of Stay in Coronary Artery Bypass Grafting. Ann Thorac Surg 2016;101:606-12; discussion 612. [PubMed] [Full text] [Crossref]

47. Sato Y, Kato TS, Oishi A, Yamamoto T, Kuwaki K, Inaba $H$, et al. Preoperative factors associated with postoperative requirements of renal replacement therapy following cardiac surgery. Am J Cardiol 2015;116:294300. [PubMed] [Full text] [Crossref]

48. Trainor D, Borthwick E, Ferguson A. Perioperative management of the hemodialysis patient. Semin Dial 2011;24:314-26. [PubMed] [Full text] [Crossref]

49. Karim HMR. Is majority of requests by anesthesiologists for cardiologist consultation unjustified? Anaesth Pain \& Intensive Care 2016;20 Suppl 
1:S109-S114. [Full text]

50. Einhorn LM, Zhan M, Hsu VD, Walker LD, Moen MF, Seliger SL, et al. The frequency of hyperkalemia and its significance in chronic kidney disease. Arch Intern Med 2009;169:1156-62. [PubMed] [Full text] [Crossref]

51. Haimov M, Glabman S, Schupak E, Neff M, Burrows L. General surgery in patients on maintenance hemodialysis. Ann Surg 1974;179:863-7. [PMC Full text] [PubMed]

52. Horlocker TT, Vandermeuelen E, Kopp SL, Gogarten W, Leffert LR, Benzon HT. Regional Anesthesia in the Patient Receiving Antithrombotic or Thrombolytic Therapy: American Society of Regional Anesthesia and Pain Medicine Evidence-Based Guidelines (Fourth Edition). Reg Anesth Pain Med 2018;43:263-309. [PubMed] [Full text] [Crossref]

53. Goldstein SL, Chawla LS. Renal angina. Clin J Am Soc Nephrol 2010;5:943-49. [PubMed] [Full text] [Crossref]

54. National Institute for Clinical Excellence. Guidance on the use of ultrasound locating devices for placing central venous catheters. Technology Appraisal Guidance [TA49]. London: NICE; 2002 Oct 4 [cited 2018 0ct 28]. Available from: https://www.nice.org. uk/guidance/ta49. [Full text pdf]

55. Meersch M, Schmidt C, Zarbock A. Patient with chronic renal failure undergoing surgery. Curr Opin Anaesthesiol 2016;29:413-20. [PubMed] [Full text] [Crossref]

56. James PA, Oparil S, Carter BL, et al. 2014 evidence-based guideline for the management of high blood pressure in adults: report from the panel members appointed to the Eighth Joint National Committee (JNC 8). JAMA 2014;311:507-20. [PubMed] [Full text] [Crossref]

57. Wijeysundera DN, Sweitzer BJ. Preoperative Evaluation. In: Miller RD, Cohen N H, Eriksson LI, Fleisher LA, Wiener-Kronish JP, Young WL, editors. Miller's Anesthesia. 8th edition.
Philadelphia: Elsevier; 2015. p. 1093.

58. Schonberger RB. Anesthesia for patients with hypertension. In Nussmeier NA (editor). UpToDate. Waltham, MA: UpToDate Inc. 2018 Sept 20 [cited 2018 Oct 27]. Available from: https://www.uptodate.com/ contents/anesthesia-for-patientswith-hypertension

59. Wu X, Jiang Z, Ying J, Han Y, Chen Z. Optimal blood pressure decreases acute kidney injury after gastrointestinal surgery in elderly hypertensive patients: A randomized study: Optimal blood pressure reduces acute kidney injury. J Clin Anesth 2017;43:77-83. [PubMed] [Full text] [Crossref]

60. Monk TG, Bronsert MR, Henderson WG, Mangione MP, Sum-Ping ST, Bentt DR, et al. Association between Intraoperative Hypotension and Hypertension and 30-day Postoperative Mortality in Noncardiac Surgery. Anesthesiology 2015;123:307-19. [PubMed] [Full text] [Crossref]

61. Marenzi G, Cosentino N, Milazzo $V$, De Metrio $M$, Rubino $M$, Jeness Campodonico, et al. Acute Kidney Injury in Diabetic Patients With Acute Myocardial Infarction: Role of Acute and Chronic Glycemia. J Am Heart Assoc 2018;7(8):e008122. [PubMed] [Full text] [Crossref]

62. Berhe Y W, Gebregzi AH, Endalew NS. Guideline on peri-operative glycemic control for adult patient with diabetic mellitus: Resource limited areas. Int J Surg Open 2017;9:1-6. [Full text] [Crossref]

63. Alexanian SM, McDonnell ME, Akhtar S. Creating a Perioperative Glycemic Control Program. Anesthesiol Res Pract 2011;2011:465-74. [Full text] [Crossref]

64. Karim HMR, Janardhan AL, Prakash A, Sahoo SK, Rajaram N, Narayan A. An Observational Study on Prevalence and Perioperative Impact of Arterial Hypertension and Diabetes Mellitus among Adult Surgical Patients. Acad Anesthesiol Int 2017;2:3-8. [Full text]
[Crossref]

65. Payen D, de Pont AC, Sakr Y, Spies C, Reinhart K, Vincent JL; Sepsis Occurrence in Acutely III Patients (SOAP) Investigators. A positive fluid balance is associated with a worse outcome in patients with acute renal failure. Crit Care 2008;12:R74. [PubMed] [Full text] [Crossref]

66. Teixeira C, Garzotto F, Piccinni P, Brienza N, lannuzzi M, Gramaticopolo $\mathrm{S}$, et al; NEFROlogia e Cura INTensiva (NEFROINT) investigators. Fluid balance and urine volume are independent predictors of mortality in acute kidney injury. Crit Care 2013;17:R14. [PubMed] [Full text] [Crossref]

67. Myburgh JA, Finfer S, Bellomo R, Billot L, Cass A, Gattas D, et al ; CHEST Investigators; Australian and New Zealand Intensive Care Society Clinical Trials Group. Hydroxyethyl starch or saline for fluid resuscitation in intensive care. N Engl J Med 2012;367:1901-11. [PubMed] [Full text] [Crossref]

68. Perner A, Haase N, Guttormsen $A B$, Tenhunen J, Klemenzson G, Åneman A, et al; 6S Trial Group; Scandinavian Critical Care Trials Group. Hydroxyethyl starch 130/0.42 versus Ringer's acetate in severe sepsis. N Engl J Med 2012;367:124-34. [PubMed] [Full text] [Crossref]

69. De Rosa S, Samoni S, Villa G, Ronco C. Management of Chronic Kidney Disease Patients in the Intensive Care Unit: Mixing Acute and Chronic Illness. Blood Purif 2017;43:151-62. [PubMed] [Full text] [Crossref]

70. Palevsky PM. Renal replacement therapy (dialysis) in acute kidney injury in adults: Indications, timing, and dialysis dose. In Lam $A Q$ (editor). UpToDate. Waltham, MA: UpToDate Inc. 2018 Jan 19 [cited 2018 Oct 25]. Available from: https://www.uptodate. com/contents/renal-replacementtherapy-dialysis-in-acute-kidneyinjury-in-adults-indications-timingand-dialysis-dose 